\title{
Corisande Fenwick, Early Islamic North Africa. A NEW PERSPECTIVE, LondRes, BloOMSBURY Academic Publishing - Debates in Archaeology, 2021, 224 PÁGS. ISBN: 9781350075184.
}

\author{
Ana Mateos-Orozco \\ Universidad de Sevilla
}

La aportación de Corisande Fenwick (University College of London) con esta obra es más que necesaria en el ámbito de la Arqueología Islámica y, especialmente, en los estudios sobre la Alta Edad Media Islámica. El título, simple pero esclarecedor, Early Islamic North Africa. A New Perspective es humilde en señalar "una nueva perspectiva" cuando en realidad esta obra supone uno de los únicos compendios sobre la realidad del mundo islámico temprano en el Norte de África. Los trabajos arqueológicos sobre la Conquista Islámica, la islamización y los primeros momentos de la expansión del Islam están en auge desde las últimas dos décadas, no obstante, estas aproximaciones aún no son suficientes para esbozar una visión de conjunto realmente completa. Además, el registro arqueológico de este periodo es en ocasiones excesivamente complejo y desconocido, lo que hace que en algunos casos sea prácticamente imposible de identificar. Esta realidad se magnifica en el Norte de África, un territorio que como bien indica la autora ha estado dominado en la investigación científica por una serie de dinámicas heredadas del colonialismo y los diferentes discursos imperialistas europeos. Por ello, los estudios tradicionales sobre las impresionantes y monumentales ciudades romanas norteafricanas, e incluso el pasado prerromano, han gozado de mayor popularidad durante el siglo XX frente a otros periodos históricos. La mayoría de estas intervenciones ponían su foco en localizar elementos del pasado romano y no solo ignoraban los niveles islámicos, sino que en muchos casos los restos llegaron a ser totalmente destruidos.

Esta tendencia afortunadamente está en proceso de cambio desde las últimas dos décadas y se están desarrollando proyectos de investigación sistemáticos que están aportando una importantísima información sobre lugares de gran relevancia como Volubilis, al Basra o Raqqada, entre otras. Del mismo modo, recientemente se han publicado obras de carácter colectivo con interesantes aportaciones a la arqueología altomedieval norteafricana ${ }^{1}$. Aun así, la autora recalca que siguen existiendo zonas en las que este periodo cuenta

\footnotetext{
Para más información consultar: Cressier, P. y Fentress, E. (eds.) 2011: La Céramique Maghrébine du Hâut Moyen Age (VIIIe-Xe Siècle). État des recherches, problemes et perspectives. École Française de Rome. Anderson, G. D., Fenwick, C. y Rosser-Owen, M. (eds.) 2018: The Aghlabids and their Neighbors Art and
} 
con escasos, por no decir nulos, estudios y proyectos, como es el caso de Libia. La problemática en el estudio de este momento de transición se incrementa con la separación tradicional e incluso metodológica entre los investigadores de la Tardoantigüedad y los de la Edad Media pese a tratarse de dos periodos que se intercalan en el tiempo. La experiencia profesional de Fenwick en la investigación de ambos periodos es notable y prueba con creces la necesidad de aunar ambas tradiciones investigadoras para lograr responder a preguntas clave sobre el proceso de formación del mundo islámico.

La obra cuenta con ocho capítulos en los que se analizan diferentes aspectos independientes a simple vista, pero que se complementan en el texto a la perfección. Los apartados son los siguientes: Una introducción a la problemática; Fundaciones: Evidencia e Interpretación; De la Conquista al Dominio Islámico; Ciudades; El Campo; Vida Económica; Vida Social; Epílogo: El Norte de África y el Mundo Islámico.

La parte introductoria es extraordinariamente útil como estado de la cuestión de la investigación tardoantigua e islámica temprana en el Norte de África, recogiendo además en esta inmensa recopilación bibliográfica las más relevantes crónicas árabes existentes. Al igual que ocurre en la península ibérica, estas fuentes no son primarias en ningún caso, y suponen grandes lagunas sobre estos primeros años de dominio islámico. Fenwick afirma, ante esta tesitura, que la Historia Islámica depende sin duda alguna de la arqueología para poder esbozar un relato completo del proceso de la conquista.

Frente a otras obras de carácter más específico, es el carácter general de esta publicación lo que la sitúa como una aportación novedosa y diferente, abordando conjuntamente aspectos materiales, socioeconómicos, culturales, etc. A nivel económico, el siglo VIII parece responder a un proceso de recuperación de una crisis previa comenzada en la tardoantigüedad. Estaremos frecuentemente ante sistemas de microeconomía y comercio local, siendo por tanto extremadamente difícil el poder observar actividades económicas y comerciales en estos momentos a través del registro arqueológico. Aun así, desde muy temprano, sí que se observa una rápida reestructuración administrativa y económica, aunque los cambios más notables se darán a partir del siglo IX y continuarán durante los siglos X y XI.

En cuanto a la islamización de la sociedad, la autora insiste en que el concepto de islamización debe entenderse en la actualidad como la adopción y difusión de las formas de vida islámica, incluyendo esto todas aquellas practicas sociales, políticas y culturales, y no únicamente las religiosas ${ }^{2}$, mientras que el término arabización hace referencia a la difusión del uso del lenguaje. De esta forma, la islamización se puede valorar a desde los menajes domésticos a las formas constructivas, los recetarios e incluso las prácti-

\footnotetext{
Material Culture in Ninth-Century North Africa. Handbook of Oriental Studies. Section 1 The Near and Middle East, Volume: 122.

2 Carvajal López, J. C., 2013: "Islamization or Islamizations? Expansion of Islam and Social Practice in the Vega of Granada (South-East Spain)". World Archaeology 45, pp. 109-123; Gutiérrez Lloret, S. 2011: "Histoire et Archéologiede la transition en al-Andalus: les índices matériels de l'islamisation à Tudmir". En D. Valérian (ed.) Islamisation et arabisation de l'Occident musulmán médiéval: VIIe-XIIe siècle. París, Publications de la Sorbonne, pp. 195-246.
} 
cas culinarias. Al mismo tiempo, Fenwick apuesta por una interpretación del registro arqueológico muy completa y rica, y analiza de manera paralela y a la vez conjunta el mundo rural y el urbano entendiéndolos en una relación simbiótica.

El amplio territorio geográfico representado en la obra permite comparar la realidad de la Conquista Islámica en lugares con sustratos poblacionales muy diversos, de influencia tardorromana, vándala y bizantina, sin olvidar aquellos territorios en los que las comunidades tribales eran protagonistas. Esta aproximación nos permite contrastar el proceso en un espacio geográfico tan amplio, diferente y complejo como es el Norte de África. Durante los siglos VII y VIII Ifriquiya y el Maghreb fueron dos zonas claramente diferenciadas: mientras Ifriquiya suponía toda la costa mediterránea de dominio e influencia bizantina, el Maghreb, en el extremo noroccidental respondía a dinámicas tribales, resultado de tradiciones tardorromanas y autóctonas.

El éxito de esta publicación radica en la puesta en común de los diferentes contextos bibliográficos, arqueológicos, culturales y geográficos para lograr obtener, aún con información muy escasa, una visión de conjunto de la sociedad norteafricana en el siglo VIII, en los márgenes del proceso de islamización. Esta obra es crucial para entender el siglo VIII en el Norte de África y completar el puzle de la expansión del Islam y los primeros años del Imperio Islámico en todo el Mediterráneo. Como señala la autora, tanto en el Norte de África como en otros territorios queda todavía mucho trabajo por hacer para responder al debate común sobre la ruptura o continuidad en el tránsito entre las épocas tardoantigua e islámica. ¿Dejará de ser invisible el siglo VIII al ojo arqueológico en los próximos años? 